\title{
Occurrence and Development of the Cereal Cyst Nematode (Heterodera avenae) in Shandong, China
}

Hai Yan Wu and Qiong He, Agricultural College of Guangxi University, Nanning 530004, China; Jing Liu and Jian Luo, College of Plant Protection, Shandong Agricultural University, Taian 271018, China; and De Liang Peng, State Key Laboratory for Biology of Plant Diseases and Insect Pests, Chinese Academy of Agricultural Sciences, 100193 Beijing

\begin{abstract}
Wu, H. Y., He, Q., Liu, J., Luo, J., and Peng, D. L. 2014. Occurrence and development of the cereal cyst nematode (Heterodera avenae) in Shandong, China. Plant Dis. 98:1654-1660.

The cereal cyst nematode (CCN), Heterodera aveane, has been found in 16 provinces of China, including the Shandong winter-wheatgrowing region. This study investigated the population dynamics of $H$. avenae in the winter wheat 'Jimai 22 ' and 'Tainong 18 ' for two consecutive years in the field. Soil and root samples were collected during the winter-wheat-growing season and $H$. avenae population densities and life-stages determined. $H$. avenae population dynamics in roots and soil of the two winter wheat cultivars were similar over the 2-year period. Second-stage juvenile (J2) population densities in wheat roots were greatest during booting stage (April), when mean soil tempera-

ture was between 11.8 and $14.4^{\circ} \mathrm{C}$. Cysts in rhizosphere soil increased significantly when new cysts were formed after Zadoks (Z) 47 (booting stage). There was a peak in $\mathrm{J} 2$ population densities in soil during Z23 and Z30 (tillering and stem elongation, respectively) whereas J2 population densities were the lowest at Z13 (seedling stage). This research provides important information indicating that $\mathrm{J} 2$ populations in roots and soil increased after the wheat winter dormancy period. Knowledge of when different life stages of $H$. avenae occur in winter wheat in Shandong will provide valuable insights to enable the development of an integrated approach to manage this plant-parasitic nematode.
\end{abstract}

Cereal cyst nematodes (CCNs), Heterodera spp., are major soilborne pathogens found in temperate wheat (Avenae sativa)-producing regions worldwide (34). Several species of Heterodera are classified as CCNs, including Heterodera avenae Wollenweber, 1924, H. bifenestra, H. gotland, H. hordecalis, and H. latipons (8); however, $H$. avenae is considered to be the most damaging and is economically important in temperate wheat-producing regions. In some wheat fields, the losses caused by $H$. avenae can range from 30 to $100 \%$ (4). In Australia, yield losses were $20 \%$ on barley (Hordeum vulgar) and 23 to $50 \%$ on wheat (15) and, in Oregon, yield losses were $24 \%$ on spring wheat (26). In Tunisia, Heterodera avenae was reported to suppress grain yields by 26 to $96 \%$ on 'Karim' wheat and 19 to $86 \%$ on 'Rihan' barley (15). Plants with roots heavily infested with $H$. avenae appear initially as pale green seedlings that lack vigor, and mature plants are often severely stunted (25). The combination of this nematode and soilborne fungi such as Rhizoctonia solani have greater effects on wheat productivity than when either pathogen is alone (12).

$H$. avenae has been reported in Australia, Canada, Israel, Japan, South Africa, and most European countries, as well as in India and several countries within North Africa, North America, and Western Asia $(15,34)$. In China, $H$. avenae was first reported in Hubei Province in 1987 (31). The distribution of $H$. avenae has expanded since this time and is now reported in wheat and barley in 15 other provinces (autonomous region or municipality) of China, including Anhui, Beijing, Gansu, Hebei, Henan, Inner Mongolia, Jiangsu, Ningxia, Qinghai, Shandong, Shanxi, Shaanxi, Tianjin, Xinjiang, and Xizang $(9,17)$. It was recently estimated that approximately 4 million ha of wheat in China are infested with $H$. avenae, indicating that this nematode is a significant problem in the wheat-producing areas of China (17).

To achieve effective control of $H$. aveane, it is necessary to reduce initial population densities below the economic damage

Corresponding author: D. L. Peng, E-mail: pengdeliang@caas.cn

Accepted for publication 28 May 2014.

http://dx.doi.org/10.1094/PDIS-08-13-0830-RE

(C) 2014 The American Phytopathological Society threshold. Management strategies implemented to achieve this reduction each require an understanding of the development and diapause (or dormancy) characteristics of the local nematode populations. Studies on population dynamics of $H$. avenae from different regions have revealed the existence of ecotypes differing in hatching cycles, which is a result of the induction or suppression of diapause under different temperature conditions $(30,35)$. Egg hatch and development requirements of the nematode are not well understood, and studying these topics is essential for understanding the biology and control of $H$. avenae.

As with other poikilothermic organisms, nematode development and reproduction are influenced by temperature $(13,16,24)$. Each species has an optimum temperature range for growth. The life cycle of $H$. avenae from egg to adult passes through four juvenile stages, of which only the second-stage juvenile (J2) can invade the roots. Temperature is an important factor for development of these $\mathrm{J} 2$ nematodes. Below a certain minimum temperature, which varies among Heterodera spp., biochemical reactions cannot continue and development stops; this temperature is known as the developmental threshold or developmental base. It has been shown that the development of insects is directly proportional to the amount of time spent above this developmental threshold (2). However, little is known about the importance of heat units (HU) required for plantparasitic nematode development (32). If HU could be used to accurately predict nematode development in relationship to wheat development, then this information could be very useful for estimating the disease epidemiology of $H$. avenae.

Here, we report the findings of a 2-year field study conducted in the major wheat-growing area of Shandong Province to clarify $H$. avenae infection characteristics and population dynamics. The specific objectives were to (i) determine the population dynamics of $H$. avenae in wheat roots and rhizosphere soil over two growing seasons, (ii) characterize the life cycle of $H$. avenae under warm temperate zone continental monsoon climatic conditions, and (iii) define the relationship between $H$. avenae development and HU.

\section{Materials and Methods}

Experimental field conditions. Two experiments were conducted during the 2009-10 and 2010-11 wheat-growing seasons at the Agronomy Experimental Station of the Shandong Agricultural 
University in the Tai'an suburb of Shandong Province in northern China $\left(36^{\circ} 09^{\prime} \mathrm{N}, 117^{\circ} 09^{\prime} \mathrm{E}\right.$, elevation $\left.134 \mathrm{~m}\right)(37)$. This area has a continental monsoon climate. The 40 -year average temperature for this region is $13.1^{\circ} \mathrm{C}$ and the average annual precipitation is 693 $\mathrm{mm}$. Daily meteorological data were obtained from Tai' an Agrometerological Experimental Station located $500 \mathrm{~m}$ from the experimental site. Rainfall during the winter-wheat-growing season during both years of this study is presented in Table 1. Soil characteristics of the field site at 0 to $40 \mathrm{~cm}$ of soil depth were organic matter at $8.8 \mathrm{~g} / \mathrm{kg}$, total $\mathrm{N}$ at $0.9 \mathrm{~g} / \mathrm{kg}$, available $\mathrm{N}$ at 65.8 $\mathrm{mg} / \mathrm{kg}$, available $\mathrm{P}$ at $11.7 \mathrm{mg} / \mathrm{kg}$, available $\mathrm{K}$ at $105.8 \mathrm{mg} / \mathrm{kg}$, and $\mathrm{pH}$ 7.1. Soil $\mathrm{pH}$ was measured in a soil-water suspension $(1: 2$, $\mathrm{vol} / \mathrm{vol}$ ) using a $\mathrm{pH}$ meter. The $\mathrm{K}$ content in soil was determined by atomic absorption spectrophotometry (1), and the P content in soil was determined colorometrically using the molybdenum blue method (1). Soil organic matter was analyzed by the potassium dichromate-volumetric method (14). Soil total $\mathrm{N}$ was determined by the Kjeldahl method (3).

Determination of initial $H$. avenae populations in soil. Initial population densities of $H$. avenae in the experimental area were determined by collecting 20 soil cores, $2.5 \mathrm{~cm}$ in diameter by 20 $\mathrm{cm}$ deep, prior to initiating experiments in both years. Collected soil was thoroughly mixed and three $100-\mathrm{cm}^{3}$ subsamples were removed. Nematodes were extracted from soil by wet sieving and sucrose flotation centrifugation procedures (20). After sucrose centrifugation, cysts were collected on a $177-\mu \mathrm{m}$ pore sieve, while $\mathrm{J} 2 \mathrm{~s}$ were collected on a $36-\mu \mathrm{m}$ pore sieve. $H$. avenae $\mathrm{J} 2 \mathrm{~s}$ were counted using a Motic SMZ-168 stereomicroscope (Motic China Group Co., Ltd.). Cysts from each sample were hand picked with a dissecting needle under a stereomicroscope and crushed with a ground-glass homogenizer to release eggs from cysts. The egg suspension $(10 \mathrm{ml})$ was then stirred, three $0.1-\mathrm{ml}$ samples were removed and placed in a counting dish, and number of eggs was determined using a stereomicroscope (23). Initial population densities of $H$. avenae are expressed as the number of encysted eggs or $\mathrm{J} 2 \mathrm{~s}$ per $100 \mathrm{~cm}^{3}$ of soil.

Experimental design, soil temperature and water content determination, and sample collection. The experimental field area was approximately 2,000 $\mathrm{m}^{2}$. Each plot was 3 by $3 \mathrm{~m}$ with 15 rows. 'Jimai 22' and 'Tainong 18' wheat, both susceptible to $H$. avenae, were flat planted using nylon mesh bags $(0.18-\mathrm{mm}$ aperture nylon mesh, $15 \mathrm{~cm}$ in diameter by $25 \mathrm{~cm}$ in depth, volume of 4.5 liter), as previously described (27). Bags were filled with a silt loam soil naturally infested with $H$. avenae from the experimental field site, with the soil volume in the bag enough to ensure devel- opment of wheat roots during the seedling stage. One seed was added to each bag. Before placing the bags in the field, approximately $60 \mathrm{~mm}$ of water was applied on 6 October 2009 and 30 September 2010. Furrows ( $25 \mathrm{~cm}$ deep) were excavated using a pick and bags containing soil and nematodes were placed into the furrow and buried on 13 October 2009 and 7 October 2010. The plants and row spacing were 15 and $20 \mathrm{~cm}$, respectively. The two cultivars were arranged in the field in a randomized complete block design with three replicates of each for a total of 20 bags in each plot. No fertilizer, irrigation, or weed control means were used during the growing season. The same field was used in both years of the experiment. The dates of seedling emergence were 25 October 2009 and 15 October 2010. Wheat plants were sampled randomly at Zadoks (Z) 13, Z21, Z23, Z25, Z27, Z28, Z30, Z37, Z47, Z65, Z85, and Z94 in each plot (36; Table 2). At each sampling date, the nylon bags, each with plant and roots intact, were removed from the plots using a shovel and placed in a plastic bag, sealed, then transported to the laboratory for analysis.

Soil temperature at depths of $5,10,15$, and $20 \mathrm{~cm}$ was recorded at 6-day intervals using four angle pipe geothermometers (Hengshui Instruments), which were installed in the center of each plot, one set per plot. Soil temperature readings were taken at 8:00, 14:00, and 18:00; the mean of the three values was considered the soil temperature for that day. Soil water content at depths of 10 and $20 \mathrm{~cm}$ was determined at each sampling time (Table 2) with a portable time-domain reflectometer CS620 system (Campbell Scientific).

Sample processing and nematode analysis. Roots and soil were removed from each bag and placed in a basin $(24 \mathrm{~cm}$ in diameter by $13 \mathrm{~cm}$ deep). Soil was gently removed from roots and then the root system was washed with water. The entire root system was weighed and then stained using the $\mathrm{NaClO}$-acid fuchsin technique (5). The stained roots were cut into small pieces with scissors and spread on a slide. Nematode population densities, including $\mathrm{J} 2 \mathrm{~s}$ and third- and fourth-stage juveniles ( $\mathrm{J} 3 \mathrm{~s}$ and $\mathrm{J} 4 \mathrm{~s}$, respectively) in the roots and white cysts on the roots, were counted using a stereomicroscope. Population densities of the various life stages are expressed as the number of nematodes per gram fresh root weight.

Soil recovered from the nylon mesh bags was mixed well and $100 \mathrm{~cm}^{3}$ of soil was used for $\mathbf{J} 2$ and cyst extraction. Soil samples were processed as described above. Nematodes collected on the $36-\mu \mathrm{m}$ pore sieve were further extracted by the sucrose flotation centrifugation method and fixed in triethanolamine-formalin (11).

Table 1. Monthly rainfall (in millimeters) during the winter wheat (Avenae sativa) growing season in Tai' an City, Shandong Province, China

\begin{tabular}{lcccccccccc}
\hline Season & October & November & December & January & February & March & April & May & June & Total \\
\hline $2009-10$ & 13 & 21 & 6 & 3 & 19 & 15 & 21 & 42 & 46 & 189 \\
$2010-11$ & 3 & 0 & 2 & 0 & 24 & 26 & 10 & 132 & 39 & 211 \\
\hline
\end{tabular}

Table 2. Growth and morphological stage of wheat (Avenae sativum) and corresponding Zadoks growth scale at sampling dates from 2009 to 2011 in Tai' an City, Shandong Province, China

\begin{tabular}{|c|c|c|c|c|}
\hline \multirow[b]{2}{*}{ Growth stages of wheat } & \multicolumn{2}{|c|}{ Sampling date } & \multirow[b]{2}{*}{ Zadoks scale $^{\mathrm{a}}$} & \multirow[b]{2}{*}{ Morphological stage } \\
\hline & 2009-10 & 2010-11 & & \\
\hline Seedling & 31 October 2009 & 23 October 2010 & Zadoks 13 & First leaf unfolded \\
\hline Tillering & 9 November 2009 & 6 November 2010 & Zadoks 21 & Main shoot and 1 tiller \\
\hline Tillering & 25 November 2009 & 30 November 2010 & Zadoks 23 & Main shoot and 3 tillers \\
\hline Tillering (winter dormancy) & 13 December 2009 & 2 January 2011 & Zadoks 25 & Main shoot and 6 tillers \\
\hline Tillering (winter dormancy) & 15 January 2010 & 20 January 2011 & Zadoks 27 & 4 leaves unfolded \\
\hline Tillering (winter dormancy) & 15 February 2010 & 12 February 2011 & Zadoks 28 & 4 leaves unfolded \\
\hline Stem elongation & 15 March 2010 & 10 March 2011 & Zadoks 30 & Pseudo stem erection \\
\hline Stem elongation & 6 April 2010 & 30 March 2011 & Zadoks 37 & Flag leaf just visible \\
\hline Booting & 21 April 2010 & 20 April 2011 & Zadoks 47 & Flag leaf sheath opening \\
\hline Anthesis & 15 May 2010 & 12 May 2011 & Zadoks 65 & Anthesis half-way \\
\hline Dough development & 3 June 2010 & 2 June 2011 & Zadoks 85 & Soft dough \\
\hline Ripening & 20 June 2010 & 22 June 2011 & Zadoks 94 & Overripe, straw dead and collapsing \\
\hline
\end{tabular}

a Plant growth stages on the Zadoks scale (36). 
Cysts and J2s were counted using a stereomicroscope and an Olympus light microscope CX21 (Olympus Corporation). The number of $\mathrm{J} 2 \mathrm{~s}$ and cysts (empty cysts, old cysts, and new cysts) in rhizosphere soil are expressed as J2s or cysts per $100 \mathrm{~cm}^{3}$.

Calculation of HU. HU accumulated each day were determined using the equation (18) $\mathrm{HU}=[\mathrm{T}(\max )+\mathrm{T}(\min )] / 2-\mathrm{T}(\mathrm{b})$, in which $\mathrm{HU}=$ heat unit accumulation for a day, $\mathrm{T}(\max )=$ maximum daily temperature in ${ }^{\circ} \mathrm{C}, \mathrm{T}(\mathrm{min})=$ minimum daily temperature in ${ }^{\circ} \mathrm{C}$, and $\mathrm{T}(\mathrm{b})=$ base temperature required for $H$. avenae egg hatch $\left(2^{\circ} \mathrm{C}\right)(7)$ and development of $\mathrm{J} 2 \mathrm{~s}\left(14^{\circ} \mathrm{C}\right)(10)$ in ${ }^{\circ} \mathrm{C}$. When $\mathrm{HU} \geq 0$, negative values for $\mathrm{HU}$ were not used.

Statistical analyses. Data collected in each year of the experiment were analyzed separately. Analysis of variance and regression equation models were performed using SPSS 12.0 Software (SPSS Inc.). When treatment means were significant at $P<0.05$, means were separated using Duncan's least significant difference test.

\section{Results}

Soil temperature and water content. The mean soil temperatures at the four soil depths were not significantly different between years $(P=0.5434)$. Soil temperatures were -0.4 to $25.4^{\circ} \mathrm{C}$ in
2009-10 and -0.3 to $25.4^{\circ} \mathrm{C}$ in $2010-11$ (Fig. 1). The lowest mean soil temperature occurred during the winter dormancy period, and was $-0.4^{\circ} \mathrm{C}(2009-10)$ and $-0.3^{\circ} \mathrm{C}(2010-11)$ at $\mathrm{Z} 27$; the soil temperature at $5 \mathrm{~cm}$ was lower in 2009-10 than in 2010-11 $(P<0.05)$, -1.6 and $1.0^{\circ} \mathrm{C}$, respectively. Soil temperature increased gradually from $\mathrm{Z} 28$, and the highest temperature was recorded at the ripening stage (Z94).

Soil moisture content at two soil depths, 10 and $20 \mathrm{~cm}$, showed the same trend during the 2-year study period and was higher at 20 $\mathrm{cm}$ than at the $10-\mathrm{cm}$ depth $(P<0.05$; Fig. 2$)$. In $2009-10$, the soil moisture content was 11.0 to $34.0 \%(10 \mathrm{~cm})$ and 12.5 to $37.5 \%(20$ $\mathrm{cm})$. Soil moisture in $2010-11$ was 8.5 to $34.0 \%(10 \mathrm{~cm})$ and 11.5 to $37.5 \%(20 \mathrm{~cm})$. The average soil moisture content was higher in 2010-11 than in 2009-10 because there was more rainfall in the 2011 spring season.

Root fresh weights and $H$. avenae population dynamics in roots. Average initial population densities of $H$. avenae in soil before planting were 866 eggs $+34 \mathrm{~J} 2 \mathrm{~s}$ (2009) and 1,530 eggs +65 J2s (2010) per $100 \mathrm{~cm}^{3}$ of soil. Winter wheat Jimai 22 and Tainong 18 had similar growth patterns during both years and were not significantly different $(P=0.5526,2009-10 ; P=0.5486,2010-11)$

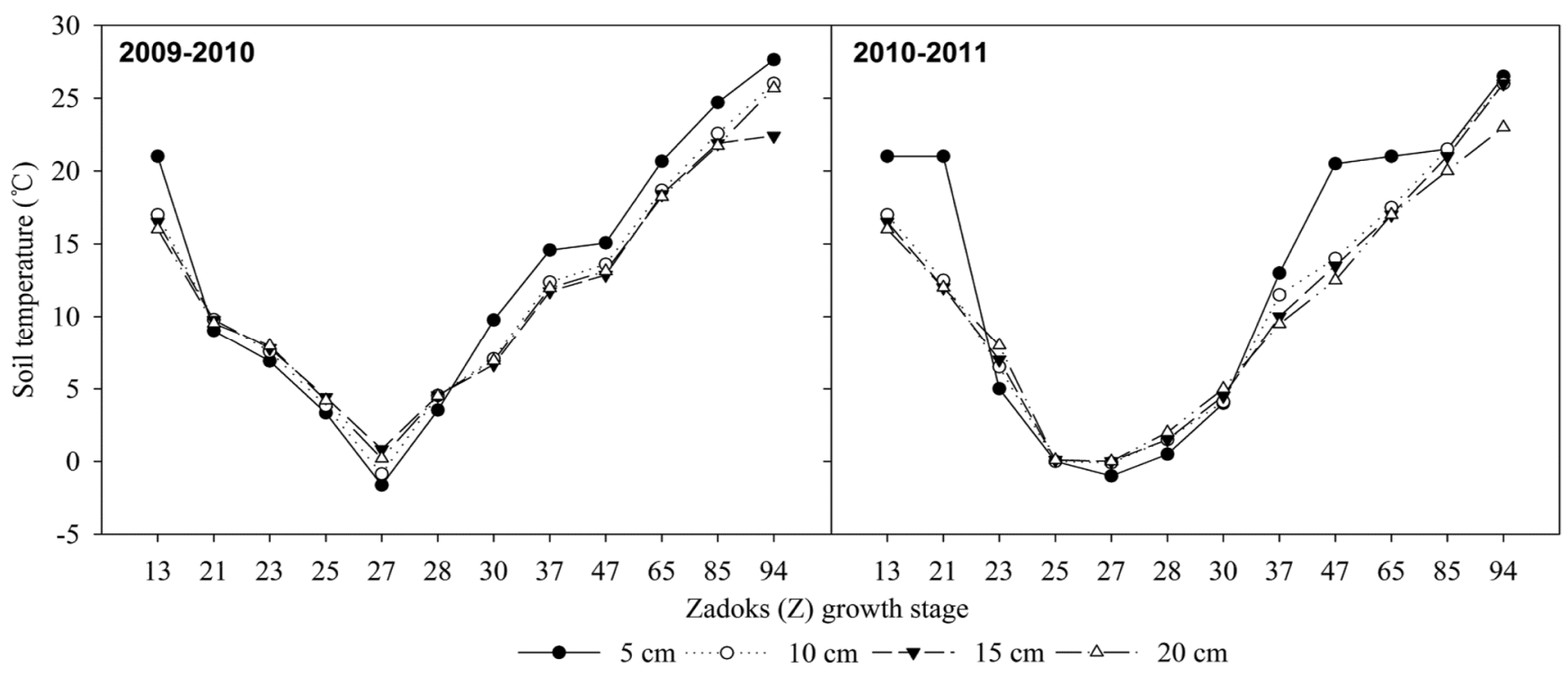

Fig. 1. Soil temperature at 5, 10,15, and $20 \mathrm{~cm}$ at Zadoks growth stages during the 2009-10 and 2010-11 wheat (Avenae sativum) growing seasons in Shandong Province, China. Each point represents the mean of three observations.

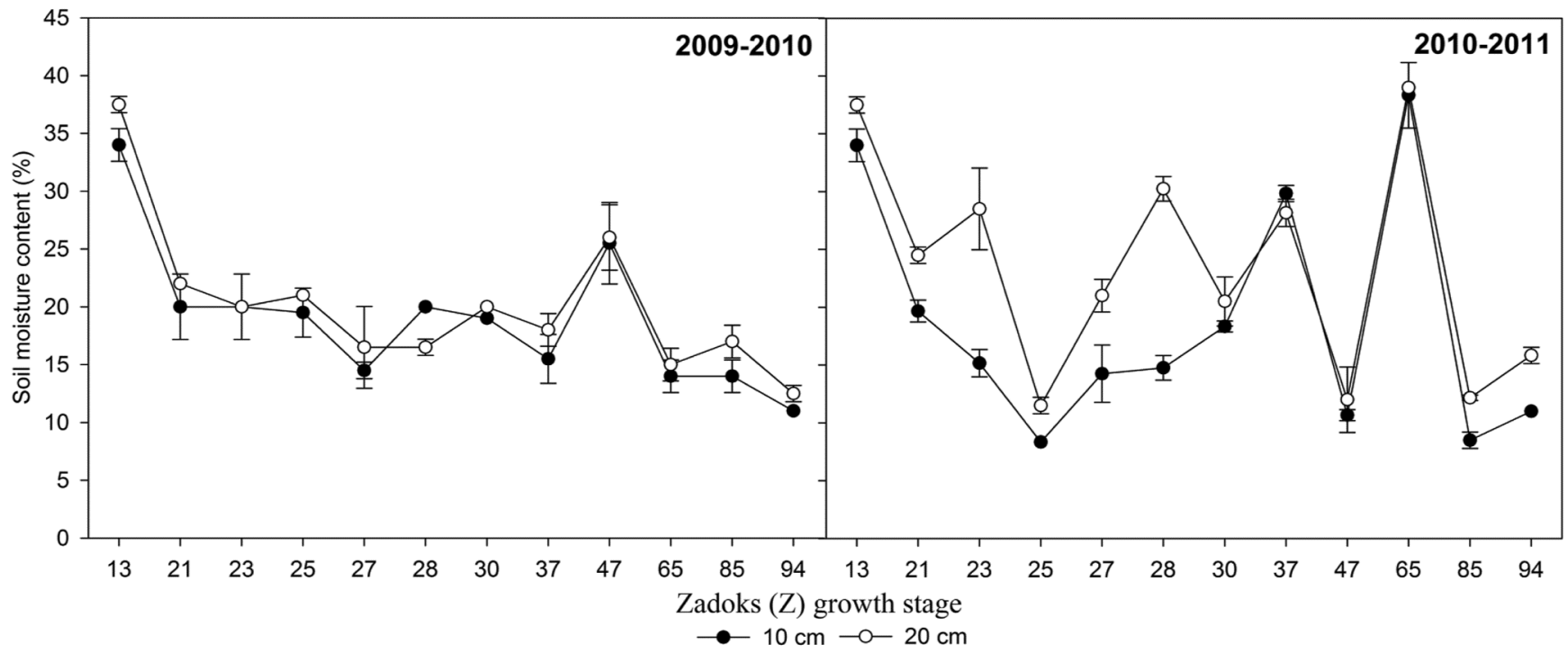

Fig. 2. Soil moisture content at 10 and $20 \mathrm{~cm}$ at Zadoks growth stages during the 2009-10 and 2010-11 wheat (Aveana sativum) growing seasons in Shandong Province, China. Each point represents the mean of three replications; vertical bars indicate standard deviation of the mean. 
(Fig. 3). Growth of both cultivars was significantly greater in 2010-11 than 2009-10, especially at Z47 and Z65 $(P=0.0001)$. In 2011, root fresh weights of Jimai 22 and Tainong 18 were 1.1 and 1.0 times greater, respectively, than that of roots in 2010. Root fresh weights of the two cultivars remained low and relatively constant before Z37. However, from Z37 to Z65, root fresh weights increased significantly with advancing growth stage $(P=0.0004$, 2009-10; $P=0.0118,2010-11)$, and decreased when roots entered senescence at the ripening stage (Z94).

The population dynamics of $H$. avenae in wheat roots in relationship to wheat growth stage during this study is also shown in Figure 3. The relationship between number of $H$. avenae and wheat growth stage was expressed as the quadratic equation $y=$ $-0.5300 x^{2}+9.0480 x-18.4621, r^{2}=0.3809(P=0.0004,2009-10)$ and $y=-0.5570 x^{2}+8.2979 x-16.2027, r^{2}=0.2560(P=0.0075$, 2010-11). Total nematodes in roots of both Jimai 22 and Tainong 18 showed similar patterns during the two growing seasons. Peak nematode population densities in the roots of Jimai 22 occurred at the anthesis stage (Z65) in 2009-10 and booting stage (Z47) in 2010-11. There was an average of $38 \mathrm{H}$. glycines nematodes/g of root at Z65 and $21 \mathrm{H}$. avenae nematodes/g of root at Z47 in Jimai 22. Peak populations of $H$. avenae in the roots of Tainong 18 occurred at the stem elongation stage (Z37) in both years, with $59 \mathrm{H}$. avenae nematodes/g of root (2009-10) and $64 \mathrm{H}$. avenae nematodes/g of root (2010-11), significantly higher than that of Jimai $22(P<0.05)$.

Infection and development of $\boldsymbol{H}$. avenae in winter wheat. Few J2s (2009-10) and no J2s (2010-11) were detected in the roots of either wheat cultivar from Z13 to Z25 (Fig. 4). J2s were found in roots of both cultivars during the earlier winter dormancy periods (Z25 and Z27). The nematode population was dominated by J2s before the booting stage (Z47), when mean soil temperature was between 11.8 and $14.4^{\circ} \mathrm{C}$. The number of nematodes per gram fresh root weight in the two cultivars increased as root growth (Fig. 3 ) and soil temperatures (Fig. 1) increased after the winter dormancy (Z28). J2s in roots increased significantly after Z27 $(P<$ $0.05)$. At the stem elongation stage, from $Z 30$ to $Z 37$, mean soil temperature at a 5 -cm depth increased from 9.8 to $14.5^{\circ} \mathrm{C}$ (200910) and from 4 to $13^{\circ} \mathrm{C}(2010-11)$. Nematode population densities in roots of Jimai 22 and Tainong 18 were the highest at Z30 and Z37, with 20 and 57 nematodes/g of root fresh weight (2009-10) and 7 and 24 nematodes/g of root fresh weight (2010-11), respectively. $\mathrm{J} 2$ population densities decreased significantly after the Z85 stage, with 1 and $2 \mathrm{~J} 2 \mathrm{~s} / \mathrm{g}$ of root fresh weight (2009-10) and 0 $\mathrm{J} 2 \mathrm{~s} / \mathrm{g}$ of root fresh weight (2010-11). The highest density of J2s was present earlier in Jimai 22 (Z30) than in Tainong 18. Population densities of $\mathrm{J} 2 \mathrm{~s}$ were significantly higher in Tainong 18 than in Jimai 22 over the 2 -year field experiment $(P<0.05)$.

In 2009-10, J3s were found at Z37, with maximum densities of $\mathrm{J} 3 \mathrm{~s}$ and $\mathrm{J} 4 \mathrm{~s}$ found at the anthesis stage (Z65, HU 4.9). In
2010-11, the highest densities of J3s and J4s were found at Z47 (HU 3.9). Meanwhile, J2 population densities decreased, and $\mathrm{J} 3 \mathrm{~s}$ composed the majority of the population, followed by rapid development until reaching maturity. Proper development of $H$. avenae from $\mathrm{J} 2$ to $\mathrm{J} 3$ and then $\mathrm{J} 4$ requires greater than 2.0 continuous daily HU. Peak numbers of J3s and $\mathrm{J} 4 \mathrm{~s}$ occurred earlier in 2010-11 (Z47) than in 2009-10 (Z65), which corresponds to the earlier occurrence of 2.0 daily HU in 2010-11 (in late April) than in 2009-10 (in May) (Fig. 4).

Different developmental stages of nematodes were found in the roots of the two wheat cultivars at the same wheat growth stage in each year. The life cycle of $H$. avenae can be calculated based on the peak occurrence of J2s and cysts. In the 2009-10 and 2010-11 growing seasons, the life cycle of $H$. avenae was completed in approximately 99 and 83 days, respectively.

Population dynamics of $\boldsymbol{H}$. avenae in rhizosphere soil of wheat. Initially, cysts recovered from soil were old and empty before new cysts were formed. The proportion of old cysts and new cysts changed significantly with wheat growth (Fig. 5). The proportion of old cysts in soil was 0 to $72 \%(2009-10)$ and 0 to $40 \%$ (2010-11) before Z65 growth stage, and the number of new cyst increased after Z65 growth stage $(P<0.05)$, with a maximum of $89 \%$ (Z85, Jimai 22) and 85\% (Z65, Tainong 18) in 2009-10 and $69 \%$ (Z65, Jimai 22) and 72\% (Z85, Tainong 18) in 2010-11.

From the unfolding of the first leaf (Z13) to flag leaf sheath opening (Z47), J2s were found in rhizosphere soil; two peaks occurred from Z13 to Z27 and from Z27 to Z47, and the number of J2s was the lowest at Z27 (the lowest soil temperature). There was no significant difference in $\mathrm{J} 2$ population dynamics between the two wheat cultivars $(P<0.05)$. From $\mathrm{Z} 13$ to $\mathrm{Z} 27, \mathrm{~J} 2 \mathrm{~s}$ were the highest in rhizosphere soil of Jimai 22 and Tainong 18, with 3 and $7 \mathrm{~J} 2 \mathrm{~s}$ per $100 \mathrm{~cm}^{3}$ of soil in $2009-10$ and 30 and $24 \mathrm{~J} 2 \mathrm{~s}$ per 100 $\mathrm{cm}^{3}$ of soil in 2010-11, respectively. From Z27 to Z47, 4 and $6 \mathrm{~J} 2 \mathrm{~s}$ per $100 \mathrm{~cm}^{3}$ of soil (2009-10) and 35 and $27 \mathrm{~J} 2 \mathrm{~s}$ per $100 \mathrm{~cm}^{3}$ of soil (2010-11) were recovered from soil at Z30 in Jimai 22 and Tainong 18, respectively. The highest $\mathrm{J} 2$ populations in soil at this stage led to the highest $\mathrm{J} 2$ densities in wheat roots and occurred at stage Z37. From Z65 (anthesis half-way) to Z94 (ripening), no J2s (2009-10) or very few J2s (2010-11) were found in rhizosphere soil of the two cultivars (Fig. 6). Egg hatch was inhibited when soil temperature was below $0^{\circ} \mathrm{C}$ and above $20^{\circ} \mathrm{C}$. At the same time, there was a negative relationship of J2s with daily $\mathrm{HU}$; J2s did not emerge from eggs when $\mathrm{HU}$ was more than 10; HU at Z21 and Z37 was 8.7 and 10.3 in 2009-10, and 9.4 and 9.6 in 2010-11, respectively (Fig. 6).

\section{Discussion}

In this study, only one generation of $H$. avenae was found during each wheat-growing season in Tai'an area, Shandong Province, China. Obligate diapause is a necessary part of the life cycle of $H$.

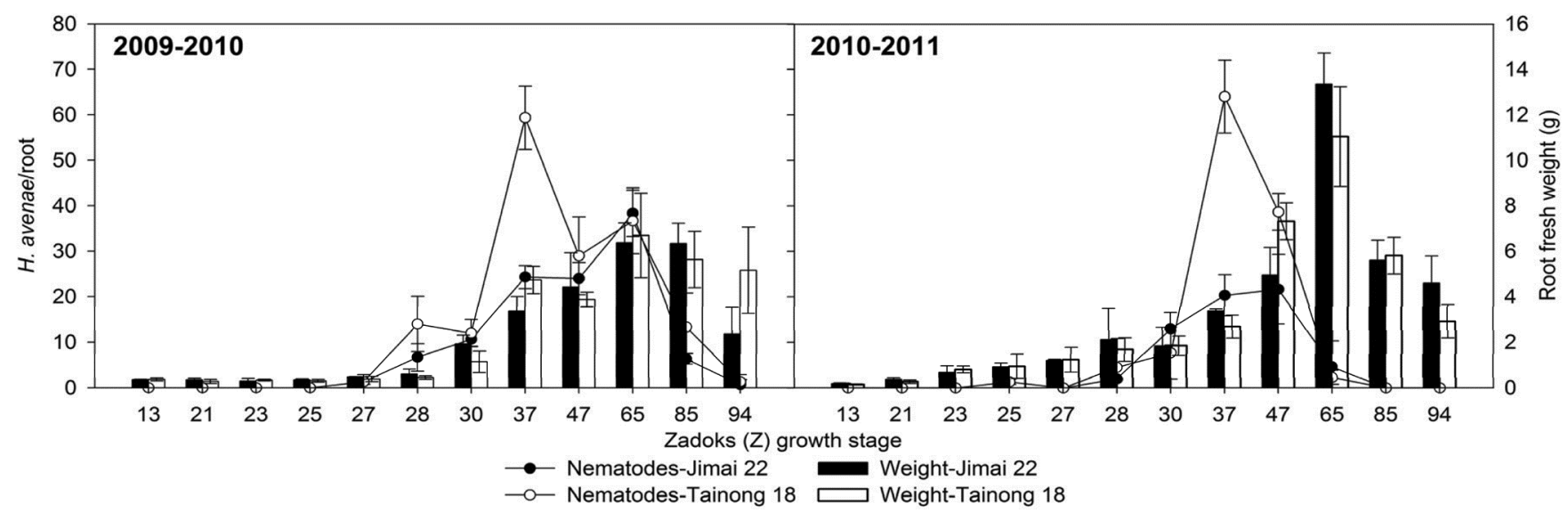

Fig. 3. Population dynamics of Heterodera avenae in wheat (Avenae sativum) roots and fresh root weights at Zadoks growth stages during the 2009-10 and 2010-11 wheat (Aveana sativum) growing seasons in Shandong Province, China. Each point represents the mean of three replications; vertical bars indicate standard deviation of the mean. 


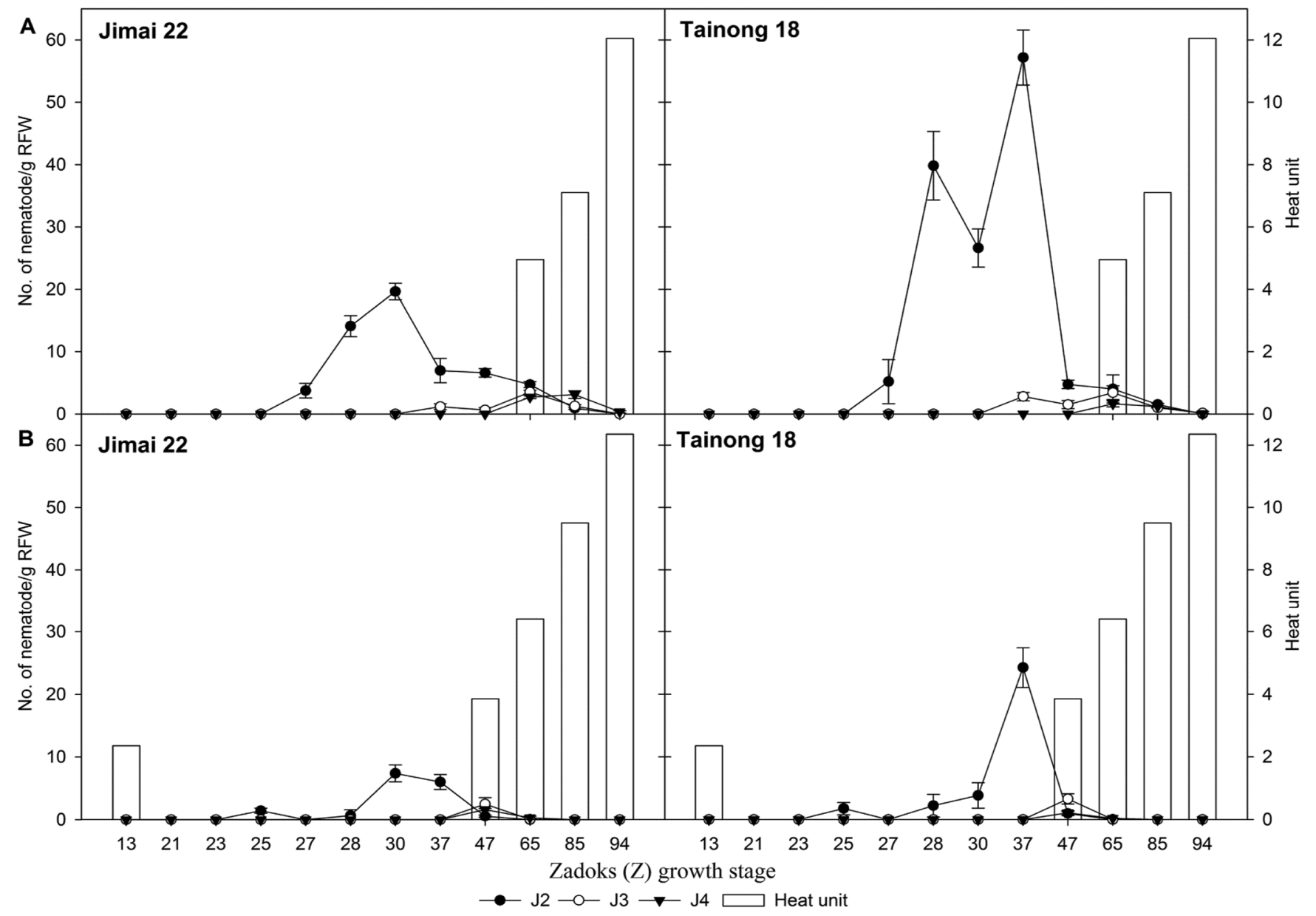

Fig. 4. Heat units and the dynamics of the development of Heterodera avenae second-, third-, and fourth-stage juveniles (J2s, J3s, and J4s, respectively) in roots (RFW) of winter wheat (Avenae sativum) 'Jimai 22' and 'Tainong 18' at Zadoks growth stages during the 2009-10 (A) and 2010-11 (B) growing seasons in Shandong Province, China. Heat units were calculated using a threshold of $14^{\circ} \mathrm{C}$ (minimum temperature necessary for $\mathrm{H}$. avenae development). Each point represents the mean of three replications; vertical bars indicate standard deviation of the mean.

avenae and, thus, only one generation of eggs is produced by the end of the host plant growing season (6). Diapause is initiated by endogenous factors long before the onset of winter temperatures. However, some populations occur in regions with hot dry summers (e.g., Australia and southern France), where the nematodes enter diapause during summer months. $H$. avenae populations from southern France needed a specific period of chilling ( 2 to 3 months at 5 to $10^{\circ} \mathrm{C}$ ) and also exhibited various levels of diapause, requiring exposure of up to four seasonal cycles before $90 \%$ hatch was attained (19). Interestingly, in this study, the population dynamics of $\mathrm{J} 2 \mathrm{~s}$ show that $H$. avenae nematodes exhibit similar response to seasonal temperatures as those in Australia and southern France, where the nematodes entered diapause during the summer months and were not induced to hatch until soil temperatures reached 5 to $10^{\circ} \mathrm{C}$, which corresponded to winter soil temperatures.

The winter period is the longest period during the winter-wheatgrowing season; nearly one-third of the life history of winter wheat occurs during this period. Root activity is important for nematode infection when winter wheat is in the winter dormancy period because aboveground growth of wheat stops during that period. However, the metabolic activities of winter wheat roots continued through the winter under Beijing climatic condition (28). In this study, the root fresh weight of winter wheat increased slowly during this period. The higher root fresh weights recorded in 2010-11 may have been caused by more rainfall later in the growing season. Although the surface soil ( 0 to $10 \mathrm{~cm})$ was frozen, below this depth wheat roots $(>10 \mathrm{~cm})$ maintained weak metabolic activity at soil temperatures of 0 to $7^{\circ} \mathrm{C}$; therefore, $\mathrm{J} 2 \mathrm{~s}$ can infect roots during the winter dormancy period (Z25 to Z28). However, it is not known whether $\mathrm{J} 2 \mathrm{~s}$ in roots can survive through the wheat winter dormancy period in the Tai' an area of Shandong Province.

Hatch and infection of $H$. glycines was reported to be closely related to root activity; nematode population densities were lower in roots during the slow growth stage and reached peak populations during the rapid growth stage (33). In this study, during the wheat winter dormancy period, soil temperature was approximately $0^{\circ} \mathrm{C}$, and few $\mathrm{J} 2 \mathrm{~s}$ invaded roots and developed when they were subjected to winter temperatures. After the winter dormancy period, soil temperatures were 3 to $10^{\circ} \mathrm{C}$, which were favorable for $\mathrm{J} 2$ invasion of roots but not favorable for nematode development; J2 was the main life stage in the roots, and J3 and J4 were not found. Soil temperatures were 10 to $20^{\circ} \mathrm{C}$ when the flag leaf was just visible (Z37), which was favorable for nematode development, and J3s and $\mathrm{J} 4 \mathrm{~s}$ were detected in the roots at this temperature range. The $\mathrm{J} 3$ and $\mathrm{J} 4$ stages increased when the mean soil temperature was between 14.4 and $25.4^{\circ} \mathrm{C}$.

$\mathrm{J} 3 \mathrm{~s}$ and $\mathrm{J} 4 \mathrm{~s}$ were detected for the first time at Z65 in 2009-10 and at Z47 in 2010-11. This difference was likely due to soil temperatures or daily $\mathrm{HU}$ from $\mathrm{Z30}$ to $\mathrm{Z} 47$; the mean soil temperature was higher in 2010-11 than in 2009-10. Meanwhile, continuous daily $\mathrm{HU}$ (HU > 2.0) came earlier in 2010-11 (the last 10 days of April) than in 2009-10 (May), leading to more rapid $H$. avenae development in 2010-11. In Hubei Province, which is $900 \mathrm{~km}$ southwest from Shandong Province, the peak J2 population was reported to occur in roots 25 to 35 days after sowing wheat in autumn, and a large number of brown cysts were found between late April and mid-May (29). There was a remarkable difference in Shandong Province, with high nematode densities in the roots 


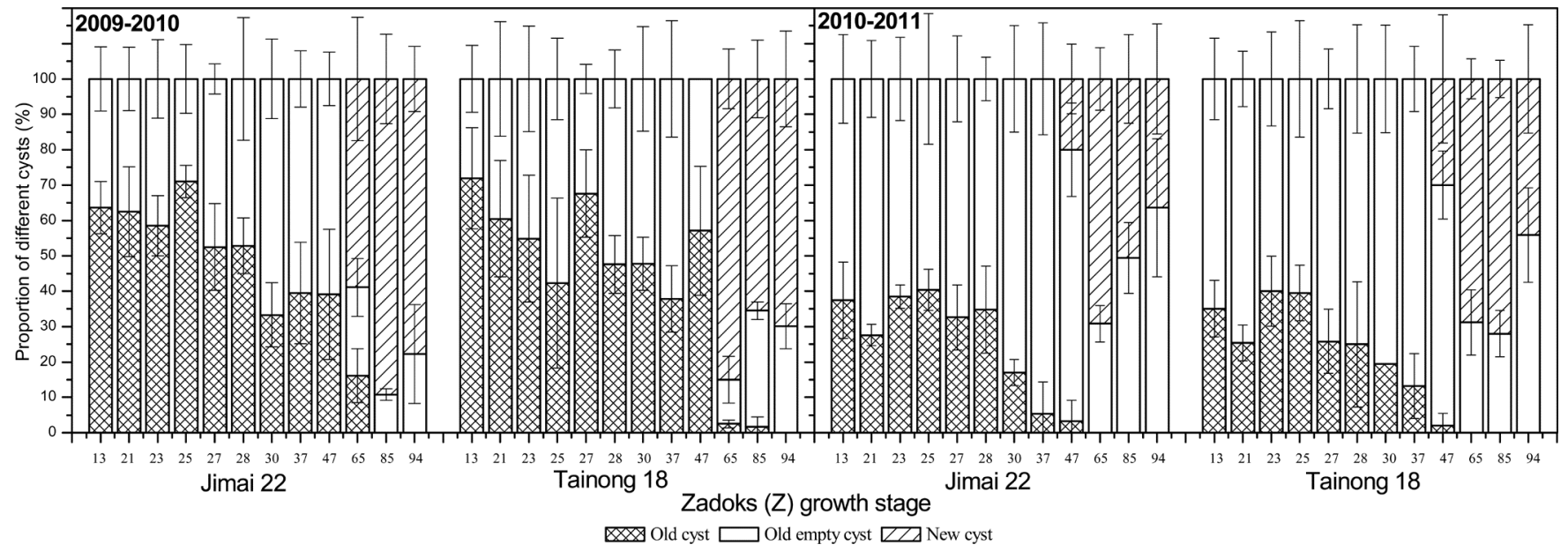

Fig. 5. Population dynamics of Heterodera avenae cysts in rhizosphere soil of winter wheat (Avenae sativum) 'Jimai 22' and 'Tainong 18' at Zadoks growth stages during the 2009-10 and 2010-11 growing seasons in Shandong Province, China. The cysts at Zadoks (Z) 65 and Z85 included new white cyst attached to roots; at Z94 stage, new cysts were collected from soil samples. Each point represents the mean of three replications; vertical bars indicate standard deviation of the mean.

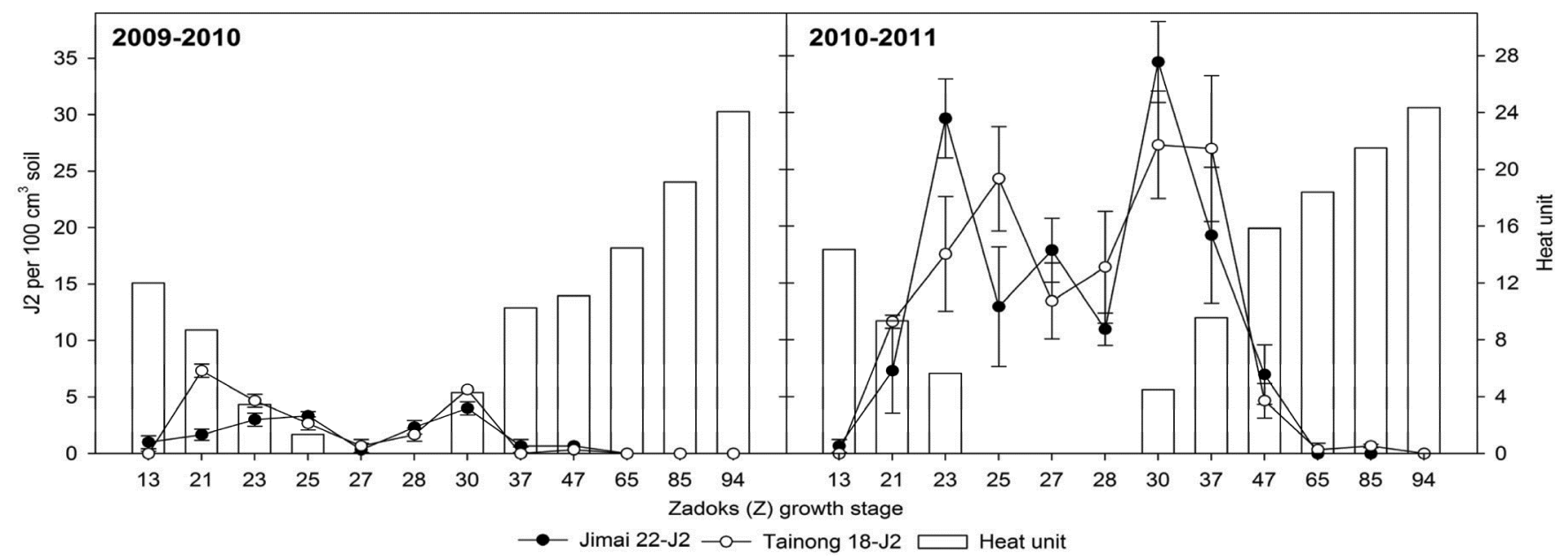

Fig. 6. Heat units and population dynamics of Heterodera avenae second-stage juveniles (J2) in rhizosphere soil of winter wheat (Avenae sativum) 'Jimai 22' and 'Tainong 18' at Zadoks growth stages during the 2009-10 and 2010-11 growing seasons in Shandong Province, China. Heat units were calculated with a threshold of $5^{\circ} \mathrm{C}$ (minimum temperature necessary for $\mathrm{H}$. avenae hatch). Each point represents the mean of three replications; vertical bars indicate standard deviation of the mean.

occurring at 141 to 146 days after seedling emergence (Z30 to Z37) and new cysts forming in early May.

The life cycle of $H$. avenae on oat was reported to be 56 days long in the Slovak Republic (21). On winter wheat, H. avenae J2s invaded roots 12 days after sowing of winter wheat in the autumn at a soil temperature of 11.5 to $14.5^{\circ} \mathrm{C}$ and continued to invade until the soil froze. Invasion of roots by $H$. avenae resumed in the spring at a soil temperature of 2.5 to $4.5^{\circ} \mathrm{C}$. The life cycle of $H$. avenae from the spring invasion to the appearance of white cysts lasted for 84 days in 1981 and for 63 days in 1982 in winter wheat (22). In this study, completion of the life cycle of $H$. avenae required 99 and 83 days in Shandong Province in 2010 and 2011, respectively.

This research demonstrated that infection of winter wheat by $H$. avenae in Shandong Province in northern China occurs mainly from Z28 (latter stage of winter wheat dormancy) to Z65 (anthesis stage). Eggs in cysts hatched and $\mathrm{J} 2$ population densities in soil significantly increased at stages from Z28 to Z30. These results provide important information about the occurrence of $H$. avenae $\mathrm{J} 2$ population dynamics and may allow for the targeting of $\mathrm{J} 2 \mathrm{~s}$ at Z28 to Z30 with chemigation or other integrated nematode management strategies. Knowledge of $H$. avenae $\mathrm{J} 2$ population dynamics in roots may also be useful for the rapid screening of wheat germplasm for resistance to $H$. avenae under field condition. For example, plants could be harvested at stages from Z37 to Z47 when peak populations of $\mathrm{J} 2 \mathrm{~s}$ are in roots. This research has provided insights into the epidemiology of $H$. avenae under Shandong climatic condition and the relationship between $H$. avenae development, wheat phenology, and daily HU which will allow for effective nematode forecasting.

\section{Acknowledgments}

This research was sponsored by the National Natural Science Foundation of China $(31460464,31101420)$, the National High Technology Research and Development Program of China (2013AA102903), the Scientific Research Foundation of GuangXi University (XGZ130781), and Guangdong Province Key Laboratory of Microbial Signals and Disease Control (MSDC-07).

\section{Literature Cited}

1. Aarnio, T., Räty, M., and Martikainen, P. J. 2003. Long-term availability of nutrients in forest soil derived from fast- and slow-release fertilizers. Plant Soil 252:227-239.

2. Agnello, A. M., Kain, D. P., and Spangler, S. M. 1993. Fruit pest events and phenological development according to accumulated heat units. N. Y. Food Life Sci. Bull. 142:1-7.

3. Bao, S. D. 2000. Agricultural Chemical Analysis of Soil. China Agriculture Press, Beijing. (In Chinese)

4. Bonfil, D. J., Dolgin, B., Mufradi, I., and Asido, S. 2004. Bioassay to forecast cereal cyst nematode dam age to wheat in fields. Precision Agric. 5:329-344.

5. Byrd, Jr., D. W., Kirkpatrick, T., and Barker, K. R. 1983. An improved technique for clearing and staining plant tissues for detection of nematodes. J. Nematol. 15:142-143. 
6. Evans, A. A. F. 1987. Diapause in nematodes as a survival strategy. Pages 180-187 in: Vistas on Nematology. J. A. Veech and D. W. Dickson, eds. Society of Nematologists, Hyattsville, MD.

7. Fushtey, S. G., and Johnson, P. W. 1966. The biology of the oat cyst nematode, Heterodera avenae in Canada. I. The effect of temperature on the hatchability of cysts and emergence of larvae. Nematologica 12:313-320.

8. Handoo, Z. A. 2002. A key and compendium to species of the Heterodera avenae group (Nematoda: Heteroderidae). J. Nematol. 34:250-262.

9. Li, H. X., Liu, Y. E., Wei, Z., and Li, M. Q. 2012. The detection of Heterodera avenae from the cereal field in Autonomous Regions of Tibet and Xinjiang. Nematol. Res. China 4:164-165. (In Chinese)

10. Li, X. H, Ma, J., and Chen, S. L. 2012. Effect of temperature on the penetration and development of Heterodera avenae. J. Triticeae Crops 32:977981. (In Chinese)

11. Liu, W. Z., ed. 1995. Plant Nematological Techniques. Liaoning Science \& Technology Press, Shenyang, China. (In Chinese)

12. Meagher, J. W., Brown, R. H., and Rovira, A. D. 1978. The effects of cereal cyst nematode (Heterodera avenae) and Rhizoctonia solani on the growth and yield of wheat. Aust. J. Agric. Res. 29:1127-1137.

13. Mokabli, A., Valette S., Gauthier, J. P., and Rivoal, R. 2001. Influence of temperature on the hatch of Heterodera avenae Woll. populations from Algeria. Nematology 3:171-178.

14. Nanjing Soil Institute of China Science Academy. 1978. Soil Physical and Chemical Analysis, Shanghai. Science and Technology Publisher. (In Chinese)

15. Nicol, J. M., and Rivoal, R. 2008. Global knowledge and its application for the integrated control and management of nematodes on wheat. Pages 251295 in: Integrated Management and Biocontrol of Vegetable and Grain Crops Nematodes. A. Ciancio and K. G. Mukerji, eds. Springer, Berlin.

16. O'Bannon, J. H., and Santo, G. S. 1984. Effect of soil temperature on reproduction of Meloidogyne chitwoodi and M. hapla alone and in combination on potato and $M$. chitwoodi on rotation plants. J. Nematol. 16:309-312.

17. Peng, D. L., Huang, W. K., Sun, J. H., Liu, C. J., and Zhang, H. M. 2012. First report of cereal cyst nematode (Heterodera avenae) in Tianjin, China. Nematol. Res. China 4:162-163. (In Chinese)

18. Perry, K. B., and Wehner, T. C. 1996. A heat unit accumulation method for predicting cucumber harvest date. HortTechnology 6:27-30.

19. Perry, R. N., and Wright, D. J. 1998. The Physiology and Biochemistry of Free-Living and Plant-Parasitic Nematodes. CABI Publishing, Wallingford, UK.

20. Riggs, R. D., Wrather, J. A., Mauromoustakos, A., and Rakes L. 2000. Planting date and soybean cultivar maturity group affect population dynamics of Heterodera glycines, and all affect yield of soybean. J. Nematol. 32:334-342.

21. Sabová, M., Lišková, M., and Valocká, B. 1985. Ontogenesis of cereal cyst nematode Heterodera avenae on oat under the climatic condition of Slo- vakia. Helminthologia 22:285-292.

22. Sabová, M., Lišková, M., and Valocká, B. 1985. Ontogenesis of the cereal cyst nematode, Heterodera avenae Wollenweber, 1924 on winter wheat under the climatic conditions of Slovakia. Helminthologia 22:293-298.

23. Seinhorst, J. W., and Den Ouden, H. 1966. An improvement of Bijloo's method for determining the egg content of Heterodera cysts. Nematologica 12:170-171.

24. Singh, M., and Sharma, S. B. 1995. Infectivity, development, and reproduction of Heterodera cajani on pigeonpea: Influence of soil moisture and temperature. J. Nematol. 27:370-377.

25. Smiley, R. W., and Nicol, J. M. 2009. Nematodes which challenge global wheat production. Pages 171-187 in: Wheat: Science and Trade. B. F Carver, ed. Wiley-Blackwell, Ames, IA.

26. Smiley, R. W., Whittaker, R. G., Gourlie, J. A., Easley, S. A., and Ingham, R. E. 2005. Plant-parasitic nematodes associated with reduced wheat yield in Oregon: Heterodera avenae. J. Nematol. 37:297-307.

27. Sun, G. Y., He, Y., Zhang, R. H., and Zhang, D. P. 1996. Studies on growth and activities of soybean root. Soy. Sci. 15:317-321. (In Chinese)

28. Ts'ao, T. 1962. The physiological activities of wheat root during winter season. Acta Sci. Nat. Univ. Pekinensis 3:298-301.

29. Wang, M., Li, S., Liu, T., and Chen, P. 1998. Characteristics of cereal cyst nematode population in active period in Hubei. Acta Phytophy. Sin. 25:3740. (In Chinese)

30. Wang, M., and Yan, J. 1993. Studies on the wheat disease caused by cyst nematode. II. Hatching of the nematode Heterodera avenae. J. Huazhong Agric. Univ. 6:561-565 (In Chinese).

31. Wang, M. Z., Peng, D. L., and Wu, X. Q. 1991. Studies on a wheat cyst nematode disease. I. Identification of pathogen. J. Huazhong Agric. Univ. 10:352-356 (In Chinese).

32. Westcott III, S. W., and Burrows, P. M. 1991. Degree-day models for predicting egg hatch and population increase of Criconemella xenoplax. J. Nematol. 23:386-392.

33. Wu, H., Wang, Z., Li, X., and Liu, J. 2011. Temporal-spatial population density of Heterodera glycines in soybean roots during the early growth stage. Nematology 13:79-86.

34. Yan, G., and Smiley, R. W. 2010. Distinguishing Heterodera filipjevi and $H$. avenae using polymerase chain reaction-restriction fragment length polymorphism and cyst morphology. Phytopathology 100:216-224.

35. Yuan, H., Yan, H., Sun, B., Xing, X., and Li, H. 2014. Infection dynamics of two species of cereal cyst nematode in Zhengzhou, Henan Province. Acta Phytopathol. Sin. 44:74-79 (In Chinese).

36. Zadoks, J. C., Chang, T. T., and Konzak, C. F. 1974. A decimal code for the growth stages of cereals. Weed Res. 14:415-421.

37. Zhou, X. B., Chen, Y. H., and Ouyang, Z. 2013. Spacing between rows: Effects on water-use efficiency of double-cropped wheat and soybean. J. Agric. Sci. Online publication. doi:10.1017/S0021859613000890 